\title{
Laparoscopic cholecystectomy versus percutaneous catheter drainage for acute cholecystitis in high risk patients (CHOCOLATE): multicentre randomised clinical trial
}

\author{
Charlotte S Loozen, ${ }^{1}$ Hjalmar C van Santvoort, ${ }^{1,2}$ Peter van Duijvendijk, ${ }^{3}$ Marc GH Besselink, ${ }^{4}$ \\ Dirk J Gouma, ${ }^{4}$ Grard AP Nieuwenhuijzen, ${ }^{5}$ Johannes C Kelder, ${ }^{6}$ Sandra C Donkervoort, ${ }^{7}$ \\ Anna AW van Geloven, ${ }^{8}$ Philip M Kruyt, ${ }^{9}$ Daphne Roos, ${ }^{10}$ Kirsten Kortram, ${ }^{1}$ \\ Verena NN Kornmann, ${ }^{1}$ Apollo Pronk, ${ }^{11}$ Donald L van der Peet, ${ }^{12}$ Rogier MPH Crolla, ${ }^{13}$ \\ Bert van Ramshorst, ${ }^{1}$ Thomas L Bollen, ${ }^{14}$ Djamila Boerma ${ }^{1}$
}

For numbered affiliations see end of article.

Correspondence to: D Boerma d.boerma@antoniusziekenhuis.nl Additional material is published online only. To view please visit the journal online.

Cite this as: $B M J$ 2018;363:k3965 http://dx.doi.org/10.1136/bmj.k3965

Accepted: 28 August 2018

\section{ABSTRACT}

OBJECTIVE

To assess whether laparoscopic cholecystectomy is superior to percutaneous catheter drainage in high risk patients with acute calculous cholecystitis.

DESIGN

Multicentre, randomised controlled, superiority trial.

SETTING

11 hospitals in the Netherlands, February 2011 to January 2016.

PARTICIPANTS

142 high risk patients with acute calculous cholecystitis were randomly allocated to laparoscopic cholecystectomy $(n=66)$ or to percutaneous catheter drainage $(n=68)$. High risk was defined as an acute physiological assessment and chronic health evaluation II (APACHE II) score of 7 or more.

\section{MAIN OUTCOME MEASURES}

The primary endpoints were death within one year and the occurrence of major complications, defined as infectious and cardiopulmonary complications within one month, need for reintervention (surgical, radiological, or endoscopic that had to be related to acute cholecystitis) within one year, or recurrent biliary disease within one year.

RESULTS

The trial was concluded early after a planned interim analysis. The rate of death did not differ between the laparoscopic cholecystectomy and percutaneous catheter drainage group ( $3 \% \vee 9 \%, \mathrm{P}=0.27)$, but major complications occurred in eight of 66 patients
(12\%) assigned to cholecystectomy and in 44 of 68 patients (65\%) assigned to percutaneous drainage (risk ratio $0.19,95 \%$ confidence interval 0.10 to $0.37 ; \mathrm{P}<0.001)$. In the drainage group 45 patients $(66 \%)$ required a reintervention compared with eight patients (12\%) in the cholecystectomy group $(\mathrm{P}<0.001)$. Recurrent biliary disease occurred more often in the percutaneous drainage group (53\% v 5\%, $\mathrm{P}<0.001$ ), and the median length of hospital stay was longer ( 9 days $\vee 5$ days, $\mathrm{P}<0.001$ ).

\section{CONCLUSION}

Laparoscopic cholecystectomy compared with percutaneous catheter drainage reduced the rate of major complications in high risk patients with acute cholecystitis.

TRIAL REGISTRATION

Dutch Trial Register NTR2666.

\section{Introduction}

Acute cholecystitis is a common indication for hospital admission and an increasing burden on the Western healthcare system. In the United States, the number of hospital admissions for acute cholecystitis increased by 44\% during 1997-2012, from 149661 to $215995 .^{1}$

In young, otherwise healthy patients early laparoscopic cholecystectomy is considered the treatment of choice for acute calculous cholecystitis. ${ }^{2}$ In high risk patients the management of acute cholecystitis remains controversial. Cholecystectomy in these patients can lead to serious morbidity and mortality owing to reduced physiological reserve. ${ }^{3-6}$ Therefore, imaging guided percutaneous catheter drainage is increasingly being performed as an alternative to early cholecystectomy. This minimally invasive radiological procedure resolves local and systemic inflammation without the risks of surgery. According to international guidelines, it is a valuable treatment in high risk patients and in those with moderate or severe cholecystitis. ${ }^{7}$ A drawback of percutaneous catheter drainage, however, is that it is not a definitive treatment since the gallbladder is not removed. This may lead to recurrent cholecystitis, and other biliary complications with severe clinical effects. $^{89}$

No randomised studies have compared laparoscopic cholecystectomy with percutaneous catheter drainage in patients with acute cholecystitis. It therefore remains 
unclear which treatment should be preferred in terms of clinical and economical outcomes. In daily practice, both cholecystectomy and percutaneous catheter drainage are performed according to the preference of the treating surgeon, gastroenterologist, or other clinicians.

We performed a nationwide randomised trial (CHOCOLATE) to assess whether laparoscopic cholecystectomy is superior to percutaneous catheter drainage in high risk patients with acute calculous cholecystitis.

\section{Methods}

\section{Study design and participants}

The CHOCOLATE study was designed as a multicentre, randomised controlled, superiority trial, and the protocol has been previously described. ${ }^{10}$ Adults with acute calculous cholecystitis and a high surgical risk were enrolled in 11 teaching hospitals in the Netherlands. Acute cholecystitis was defined according to the Tokyo guidelines. ${ }^{11}$ Risk assessment was based on the APACHE II (acute physiology assessment and chronic health evaluation II) severity of disease classification system. ${ }^{12}$ High risk was defined as an APACHE II score of 7 or more. We chose this cut-off on the basis of systematic evaluation of several imaginary case scenarios by a multicentre, multidisciplinary expert panel of surgeons, gastroenterologists, and radiologists. Patients with an APACHE II score of 15 or more were excluded because the risk of mortality in these patients was deemed too high-that is, disease severity or comorbidity, or both, presented a strict contraindication to surgery. We also excluded patients with symptoms that lasted longer than seven days at time of first presentation, since these patients should undergo delayed cholecystectomy according to the Dutch treatment guidelines. ${ }^{13}$ Other exclusion criteria were pregnancy, decompensated liver cirrhosis, admission to the intensive care unit at the time of cholecystitis diagnosis, and mental illness prohibiting informed consent.

The study was investigator initiated and conducted in accordance with the principles of the Declaration of Helsinki. The protocol was approved by the institutional review board of each participating centre. The safety and efficacy of the trial was monitored by a data safety monitoring board consisting of three independent, non-participating clinicians and an independent epidemiologist. All patients or their legal representatives provided written informed consent.

\section{Randomisation and masking}

Patients were randomly assigned to either laparoscopic cholecystectomy or percutaneous catheter drainage, both to be performed within 24 hours after randomisation. A central study coordinator carried out randomisation using an online module and permuted block randomisation with varying block sizes with a maximum block size of four patients. Randomisation was stratified according to treatment centre. Owing to the invasive nature of the intervention and the logistics involved in carrying out the procedures, neither the trial participants nor the investigators could be masked to group allocation.

\section{Procedures}

Laparoscopic cholecystectomy was performed by the four trocar technique, with transection of the cystic duct and artery after reaching the critical view of safety, as described in national and international guidelines. ${ }^{13} 14$ The procedures were performed by surgeons experienced in laparoscopic surgery, defined as performing more than 100 laparoscopic procedures yearly. Patients received a single dose of preoperative antibiotic prophylaxis according to the local hospital protocol.

Percutaneous catheter drainage was performed under local anaesthesia and aseptic circumstances, with image guidance using either ultrasonography or computed tomography. The procedures were performed by, or under direct supervision of, qualified radiologists. A certain experience to undertake this procedure was not required, as percutaneous catheter drainage is reported to be a relatively easy procedure, performed by any radiologist in the Netherlands. Gallbladder puncture was directed through the transhepatic or transperitoneal route, depending on the preference of the radiologist and the location of the gallbladder. For placement of the pigtail catheter into the gallbladder, either the trocar technique (one step technique) or the Seldinger technique (multiple step technique) was used. Emergency cholecystectomy was performed in case of clinical deterioration, persisting fever, or an increase in serum white blood cell count or $\mathrm{C}$ reactive protein within 48 hours, despite accurate position and function of the drain. Patients were discharged with the percutaneous drain. The drain was left in place for three weeks. Before removal of the drain, antegrade cholangiography was performed to assess for duodenal backflow and a patent cystic duct. Further treatment was left to the discretion of the treating clinician.

\section{Data collection and outcomes measures}

The primary endpoints were death within one year and the occurrence of major complications, defined as infectious and cardiopulmonary complications within one month, the need for reintervention within one year, or recurrent biliary disease within one year. Table 1 provides detailed definitions. Reinterventions were either surgical, radiological, or endoscopic and had to be directly or indirectly related to acute cholecystitis. Routine elective cholecystectomy after percutaneous catheter drainage was not included in the primary endpoint (ie, only cholecystectomies for recurrent gallstone related complications were considered as matching the endpoint "need for reintervention"). Recurrent biliary disease was considered an endpoint only if readmission was required (so we did not include patients with recurrent biliary disease presenting to the general practitioner or emergency department without subsequent admission to hospital). 


\begin{tabular}{|c|c|c|}
\hline Endpoint & Definition & Comment \\
\hline Death & & Within one year after randomisation \\
\hline \multicolumn{3}{|l|}{ Major complications: } \\
\hline Intra-abdominal abscess & $\begin{array}{l}\text { Fever or increased C reactive protein level/white blood } \\
\text { cell count, or both, and intra-abdominal fluid collection } \\
\text { on computed tomography or ultrasonography }\end{array}$ & Within 30 days after randomisation \\
\hline Pneumonia & $\begin{array}{l}\text { Coughing or dyspnoea, radiography with infiltrative } \\
\text { abnormalities, increased infection variable, and } \\
\text { positive sputum culture result }\end{array}$ & Within 30 days after randomisation \\
\hline Myocardial infarction & $\begin{array}{l}\text { Symptomatic increased cardiac enzyme levels and } \\
\text { abnormalities on electrocardiography or cardiac } \\
\text { ultrasonography }\end{array}$ & Within 30 days after randomisation \\
\hline Pulmonary embolism & Radiologically proven pulmonary embolism & Within 30 days after randomisation \\
\hline Need for reintervention & Surgical, endoscopic, or radiological reintervention & $\begin{array}{l}\text { Within one year after randomisation. Before analysis, the adjudication committee } \\
\text { decided to only report reinterventions directly or indirectly related to acute cholecystitis. } \\
\text { A routine elective cholecystectomy after percutaneous catheter drainage was not } \\
\text { included in the primary endpoint (ie, only cholecystectomies for recurrent gallstone } \\
\text { related complications were included) }\end{array}$ \\
\hline Recurrent biliary disease & & $\begin{array}{l}\text { Within one year after randomisation. Before analysis, the adjudication committee } \\
\text { decided to only report recurrent biliary disease when readmission was required }\end{array}$ \\
\hline
\end{tabular}

The secondary endpoints included the individual components of the primary outcome, minor complications, difficulty of cholecystectomy (as scored by a visual analogue scale from 1 to 10), utilisation of healthcare resources, and total costs. The supplementary appendix provides details on cost calculation.

Follow-up took place at the outpatient clinic three weeks after discharge and subsequently by a phone call once every month for one year. Local clinicians performed data collection using case record forms. The study coordinator verified all completed forms in accordance with onsite source data. Through consensus, two investigators not involved in patient care resolved discrepancies detected by the study coordinator.

An adjudication committee consisting of four experienced surgeons and one radiologist carried out a blinded assessment of primary and secondary outcomes. Committee members individually evaluated the data in a standardised format for every patient, including all available data collected during follow-up. Disagreement was resolved in a plenary consensus meeting, with concealment of the treatment assignment.

\section{Statistical analysis}

The sample size calculation was based on an expected reduction in the primary endpoints from $28 \%$ in the percutaneous drainage group to $15 \%$ in the cholecystectomy group. ${ }^{10}$ This was based on the results of a Dutch retrospective cohort study and a systematic review analysing the safety and effectiveness of percutaneous drainage in elderly and critically ill patients. ${ }^{615}$ To show this effect with $80 \%$ power, a two sided $\alpha$ level of $5 \%$, and a loss to follow-up of $1 \%$, we needed at least 284 patients in total.

Primary analyses were performed in accordance with a pre-established analysis plan and according to the intention to treat principle. Differences between groups were expressed as risk ratios with corresponding 95\% confidence interval. For continuous variables, we calculated differences with the student's $t$ test for normally distributed data and the Mann-Whitney U test for non-normally distributed data. We considered a two tailed $P$ value $<0.05$ to be significant. All $P$ values are two sided and not corrected for multiple testing.

In the original study protocol, ${ }^{11}$ an interim analysis for efficacy was specified after the first year of inclusion because it was anticipated that half the number of required patients would have been randomised at that time. The accrual rate was, however, slower than expected. Therefore, we conducted the interim analysis at a later stage, when half the sample size had been reached. We compared the occurrence of the primary endpoints between the treatment groups. The Peto approach was followed, meaning that the study would only be stopped for beneficial effects in case of a $\mathrm{P}$ value $<0.001$. The independent data safety monitoring board evaluated the results of the interim analysis.

\section{Patient and public involvement}

No patients were involved in setting the research question or developing plans for design of the study, nor were they asked to advise on interpretation or writing up of results. Results of the trial will be made available to all participants by email.

\section{Results}

In December 2015, a formal interim analysis for the primary endpoints was performed. Data on 138 patients were reviewed, 118 of whom had completed follow-up. The $\mathrm{P}$ value of the difference between both groups was below the prespecified threshold of 0.001 . Motivated by considerations of the beneficial effect of laparoscopic cholecystectomy and concerns about negative outcomes in the percutaneous drainage group, on 26 February 2016 the data safety monitoring board recommended termination of the trial. We followed up all patients who had undergone randomisation before this date until study completion.

Between 23 February 2011 and 30 January 2016 we assessed a total of 790 patients with acute calculous cholecystitis for eligibility, 142 of whom underwent 


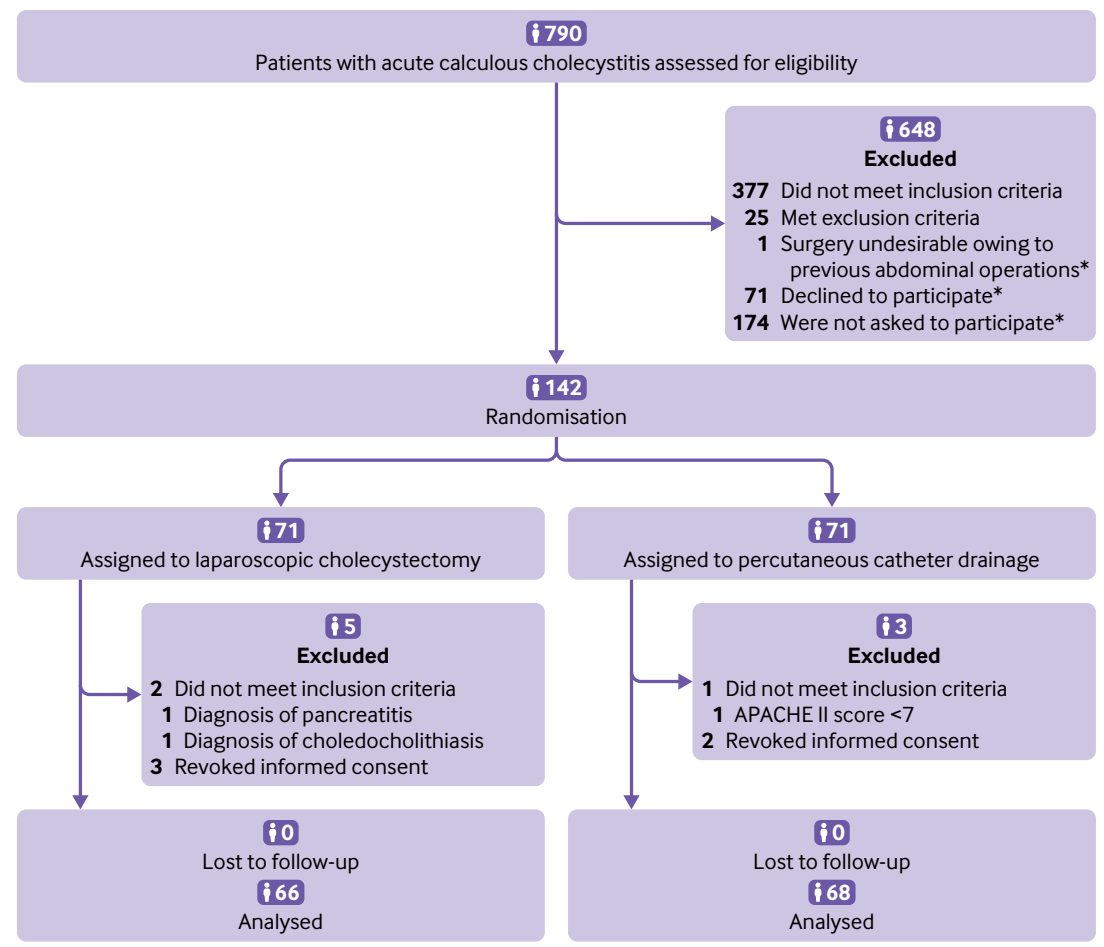

Fig 1 | Enrolment, randomisation, and follow-up of study participants. APACHE=acute physiology and chronic health evaluation. *Patients who were eligible for inclusion but did not participate in the trial. The baseline characteristics of these patients were similar to those of the included patients, with the exception of the APACHE II score, which was higher in the included group $(9.4 v 9.0)$ (see table 2 in supplementary appendix) abdominal pain. Clinical improvement within 48 hours occurred in 63 of the 68 patients (93\%). In one patient an emergency cholecystectomy was performed as a result of clinical deterioration.

The rate of death did not significantly differ between the two groups; two patients (3\%) in the cholecystectomy group and six $(9 \%)$ in the drainage group died $(\mathrm{P}=0.27)$. Deaths in the cholecystectomy group occurred during follow-up and were related to oesophageal and colorectal cancer. In the drainage group two patients died during index admission as a result of ongoing sepsis due to the acute cholecystitis, one patient died during readmission from sepsis due to recurrent cholecystitis, and one patient died at home by an unknown cause, one week after removal of the percutaneous drain. The remaining two patients died during follow-up from mesothelioma and intestinal ischaemia.

Major complications occurred in eight of the 66 patients (12\%) assigned to cholecystectomy and in 44 of the 68 patients (65\%) assigned to drainage (risk ratio 0.19 , 95\% confidence interval 0.10 to 0.37 ; $\mathrm{P}<0.001$ ) (table 3). These results did not change after post hoc adjustment for baseline differences in age and cardiovascular disease using multivariable logistic regression (adjusted odds ratio with cholecystectomy 0.08 , 95\% confidence interval 0.03 to 0.19 ; $\mathrm{P}<0.001$ ). A formal test of interaction in a logistic regression model was used to assess whether treatment effects for the primary endpoints differed between subgroups based on treatment centre, and showed no significant difference $(\mathrm{P}>0.05)$.

The difference in rate of infectious and cardiopulmonary complications as well as minor complications between the two groups was not statistically significant (table 3). Reinterventions related to cholecystitis, however, were performed less often after cholecystectomy than after drainage (12\% v 66\%, P<0.001) (table 3). Recurrent biliary disease also occurred less often in patients assigned to cholecystectomy (5\% $v 53 \%, \mathrm{P}<0.001)$ (table 3). Emergency cholecystectomy was performed in 11 of the 68 patients (16\%) assigned to percutaneous catheter drainage-in two patients (3\%) because of clinical deterioration and in nine (13\%) because of recurrent cholecystitis (table 3). Elective cholecystectomy was performed in 20 of the 68 patients $(29 \%)$ in the drainage group; in 15 patients $(22 \%)$ because of recurrent gallstone related complications and in five (8\%) because of either a dysfunctional drain or absence of duodenal backflow revealed by cholangiography. The indication for cholecystectomy in the latter five patients was, in the opinion of the adjudication committee, debatable, and therefore not considered as reaching the primary endpoint. Biliary injury occurred in four patients $(6 \%)$ in the cholecystectomy group and in two (3\%) in the drainage group, all of whom required endoscopic retrograde cholangiopancreatography. The total length of hospital stay (including readmissions) was five days (interquartile range 4-8 days) in the cholecystectomy group and nine (6-19) days in the 


\begin{tabular}{|c|c|c|}
\hline Characteristics & $\begin{array}{l}\text { Laparoscopic cholecystectomy } \\
(\mathrm{n}=66)\end{array}$ & $\begin{array}{l}\text { Percutaneous catheter drainage } \\
(n=68)\end{array}$ \\
\hline Mean (SD) age (years) & $71.4(10.6)$ & $74.9(8.6)$ \\
\hline Men & $41(62)$ & $44(65)$ \\
\hline Mean (SD) body mass index* & $28.7(5.3)$ & $29.0(5.5)$ \\
\hline \multicolumn{3}{|l|}{ Coexisting conditions: } \\
\hline Cardiovascular disease & $38(58)$ & $53(78)$ \\
\hline Pulmonary disease & $13(20)$ & $14(21)$ \\
\hline Chronic renal insufficiency & $3(5)$ & $5(7)$ \\
\hline Diabetes & $13(20)$ & $16(24)$ \\
\hline Previous abdominal surgery & $16(24)$ & $10(15)$ \\
\hline ERCP before randomisation & $3(5)$ & $4(6)$ \\
\hline \multicolumn{3}{|l|}{ ASA classification on admission: } \\
\hline I: healthy status & $10(15)$ & $4(6)$ \\
\hline II: mild systemic disease & $33(50)$ & $37(54)$ \\
\hline III: severe systemic disease & $23(35)$ & $24(35)$ \\
\hline IV: severe systemic disease that is a constant threat to life & 0 & $3(4)$ \\
\hline \multicolumn{3}{|l|}{ Disease severity: } \\
\hline Mean (SD) APACHE II scoret & $9.5(1.9)$ & $9.4(2.0)$ \\
\hline Mean (SD) C reactive protein level (mg/L) & $218.5(117.2)$ & $214.7(123.8)$ \\
\hline Mean (SD) white blood cell count $\left(\times 10^{9} / \mathrm{L}\right) \ddagger$ & $17.0(5.1)$ & $17.2(5.2)$ \\
\hline Mean (SD) body temperature $\left({ }^{\circ} \mathrm{C}\right) \S$ & $37.7(1.1)$ & $37.8(0.9)$ \\
\hline Median (interquartile range) time since onset of symptoms (days) & $3(2$ to 3$)$ & $2(1$ to 4$)$ \\
\hline \multicolumn{3}{|c|}{$\begin{array}{l}\text { ERCP=endoscopic retrograde cholangiopancreatography; ASA=American Society of Anaesthesiologists; APACHE II=acute physiology and chronic health } \\
\text { evaluation II. } \\
\text { *Data missing for } 12 \text { patients in cholecystectomy group and nine in drainage group. } \\
\text { tScores on acute physiological and chronic health evaluation II (APACHE II) Scale range from } 0 \text { to } 71 \text {, with higher scores indicating more severe disease. } \\
\text { fData missing for one patient in drainage group. } \\
\text { SData missing for five patients in cholecystectomy group and two in drainage group. } \\
\text { १IIn all patients, time since onset of symptoms was seven days or less. Data on exact number of days were missing for five patients in drainage group but } \\
\text { were reported to be less than } 7 \text {. }\end{array}$} \\
\hline
\end{tabular}

percutaneous drainage group $(\mathrm{P}<0.001)$ (table 3$)$. The total number of visits to the emergency department was seven and 56, respectively $(\mathrm{P}<0.001)$. The total number of readmissions was nine in the cholecystectomy group and 67 in the drainage group $(\mathrm{P}<0.001)$, and the total number of reinterventions was 21 and 64, respectively $(\mathrm{P}<0.001)$.

The mean direct medical costs per patient during a follow-up of one year after randomisation were $€ 4993$ (\$6125; €5568) for cholecystectomy and $€ 7427$ for drainage, with a mean absolute difference of $€ 2434$ per patient. Details of costs are given in table 1 in the supplementary appendix.

\section{Discussion}

This study showed that laparoscopic cholecystectomy is superior to percutaneous catheter drainage in the treatment of high risk patients with acute calculous cholecystitis. Cholecystectomy not only reduced the rate of major complications but also reduced utilisation of healthcare resources and costs by more than $30 \%$.

Previous studies found a high short term success rate from percutaneous catheter drainage for acute cholecystitis in high risk patients. ${ }^{6}$ 16-21 Our study supports these findings, with prompt clinical improvement in more than $90 \%$ of patients undergoing percutaneous drainage. A systematic review of 53 mostly retrospective studies, published in $2009,{ }^{6}$ analysing the safety and efficacy of percutaneous catheter drainage in elderly and critically ill patients with acute cholecystitis, found few complications (6\%) and low procedure related mortality $(0.4 \%)$, which corresponds with our finding. The reported 30 day mortality was high (13\%), which could be attributed to confounding by indication, as most patients treated with drainage included in the retrospective studies are generally in poor clinical condition. In our study, the rate of death in the drainage group was also high (9\%), but was not significantly different from that in the cholecystectomy group. The high rate of recurrent gallstone related disease in our study is reason for concern. More than half of the patients in the drainage group developed recurrent symptoms requiring (emergency) readmissions or reinterventions, or both; a much higher rate than reported in previous studies. ${ }^{17} 18 \quad 2223$ This may be explained by the randomised design of our study and the fact that we only included high risk patients.

The rate of recurrent gallstone related symptoms after drainage could have been lower if all patients would have undergone elective cholecystectomy. Routine elective cholecystectomy was not part of the study design because one of the advantages of percutaneous catheter drainage is the avoidance of complications related to surgery. For that reason, several authors suggest that high risk patients should not undergo elective cholecystectomy after percutaneous catheter drainage. ${ }^{202-26}$ Our findings, however, support routine cholecystectomy in all patients who have undergone percutaneous catheter drainage, as promoted by others. $^{27-29}$ Alternatively, only patients who are especially at risk for recurrent gallstone related disease could undergo cholecystectomy. No studies, however, 


\begin{tabular}{|c|c|c|c|c|}
\hline Outcomes & Cholecystectomy group $(n=66)$ & Drainage group $(n=68)$ & Risk ratio $(95 \% \mathrm{Cl})$ & $P$ value \\
\hline \multicolumn{5}{|l|}{ Primary endpoints* } \\
\hline Death & $2(3)$ & $6(9)$ & 0.34 (0.07 to 1.64$)$ & 0.27 \\
\hline Major complicationst & $8(12)$ & $44(65)$ & $0.19(0.10$ to 0.37$)$ & $<0.001$ \\
\hline \multicolumn{5}{|l|}{ Secondary endpoints* } \\
\hline Death: & $2(3)$ & $6(9)$ & $0.34(0.07$ to 1.64$)$ & 0.27 \\
\hline Directly/indirectly related to acute cholecystitis & 0 & $3(4)$ & & \\
\hline Unrelated to acute cholecystitis & $2(3)$ & $2(3)$ & & \\
\hline Unknown cause & 0 & $1(2)$ & & \\
\hline Infectious and cardiopulmonary complicationf: & $5(8)$ & $3(4)$ & $0.97(0.89$ to 1.05$)$ & 0.49 \\
\hline Intra-abdominal abscess & $4(6)$ & $2(3)$ & & \\
\hline Pneumonia & $2(3)$ & $1(2)$ & & \\
\hline Myocardial infarction & 0 & 0 & & \\
\hline Pulmonary embolism & 0 & 0 & & \\
\hline Need for reintervention‡: & $8(12)$ & $45(66)$ & $0.18(0.09$ to 0.36$)$ & $<0.001$ \\
\hline Surgical intervention & $3(5)$ & $32(47)$ & $0.10(0.03$ to 0.30$)$ & $<0.001$ \\
\hline Emergency cholecystectomy & NA & $11(16)$ & & \\
\hline Clinical deterioration & NA & $2(3)$ & & \\
\hline Recurrent cholecystitis & NA & $9(13)$ & & \\
\hline Elective cholecystectomy§ & $2(2)$ & $20(29)$ & & \\
\hline Recurrent gallstone related disease & NA & $15(22)$ & & \\
\hline Dysfunctional drainq & NA & $1(2)$ & & \\
\hline Absence of duodenal backflow revealed by cholangiography & NA & $4(6)$ & & \\
\hline Cholecystectomy not performed during index admission & $2(2)$ & NA & & \\
\hline Diagnostic laparoscopy & $1(2)$ & $1(2)$ & & \\
\hline Endoscopic intervention & $6(9)$ & $11(16)$ & $0.56(0.22$ to 1.43$)$ & 0.22 \\
\hline ERCP & $6(9)$ & $11(16)$ & & \\
\hline Choledocholithiasis & $2(3)$ & $9(13)$ & & \\
\hline Biliary injury & $4(6)$ & $2(3)$ & & \\
\hline Removal of biliary stent & $1(2)$ & 0 & & \\
\hline Radiological intervention & $4(6)$ & $15(22)$ & $0.28(0.10$ to 0.79$)$ & 0.008 \\
\hline Percutaneous catheter drainage & NA & $8(12)$ & & \\
\hline Recurrent cholecystitis & NA & $6(9)$ & & \\
\hline Dysfunctional drain & NA & $2(3)$ & & \\
\hline Drainage abscess & $3(5)$ & $4(6)$ & & \\
\hline Drainage biloma & $2(3)$ & 0 & & \\
\hline Drainage ascites & 0 & $1(2)$ & & \\
\hline Antegrade cholangiography & NA & $4(6)$ & & \\
\hline Contrast image PTC tube & $1(2)$ & 0 & & \\
\hline Recurrent biliary disease $\neq:$ & $3(5)$ & $36(53)$ & $0.09(0.03$ to 0.27$)$ & $<0.001$ \\
\hline Requiring emergency readmission & $3(5)$ & $28(41)$ & & \\
\hline Requiring planned readmission & $2(3)$ & $16(24)$ & & \\
\hline Elective cholecystectomy & NA & $15(22)$ & & \\
\hline ERCP & $2(3)$ & $3(4)$ & & \\
\hline Minor complication: & 0 & $4(6)$ & & 0.12 \\
\hline Wound infection & 0 & $2(3)$ & & \\
\hline Bleeding & 0 & 0 & & \\
\hline Urinary tract infection & 0 & $2(3)$ & & \\
\hline \multicolumn{5}{|l|}{ Healthcare utilisation: } \\
\hline Median (interquartile range) length of stay after randomisation (days) & $4(3-6)$ & $6(4-8)$ & & 0.01 \\
\hline Median (interquartile range) total length of hospital stay (days) & $5(4-8)$ & $9(6-19)$ & & $<0.001$ \\
\hline Median (interquartile range) total length of stay in ICU (days) & $0(0-0)$ & $0(0-0)$ & & 0.16 \\
\hline Total No (range per patient) of ER visits per study group & $7(0-1)$ & $56(0-5)$ & & $<0.001$ \\
\hline Total No (range per patient) of reinterventions per study group & $21(0-6)$ & $64(0-4)$ & & $<0.001$ \\
\hline Total No (range per patient) of readmissions per study group & $9(0-2)$ & $67(0-5)$ & & $<0.001$ \\
\hline \multicolumn{5}{|c|}{$\begin{array}{l}\text { ERCP=endoscopic retrograde cholangiopancreatography; PTC=percutaneous transhepatic cholangiography; ICU=intensive care unit; ER=emergency department; NA=not applicable. } \\
\text { *Multiple events in same patient were considered as one endpoint. } \\
\text { tFor example, infectious and cardiopulmonary complications within one month, need for reintervention within one year, or recurrent biliary disease within one year. } \\
\text { fIncluded in primary endpoint of major complications. } \\
\text { \$Elective cholecystectomies were not included in primary endpoint, unless performed for recurrent gallstone related disease. } \\
\text { qThese procedures were not included in primary endpoint because the adjudication committee judged the indication debatable. }\end{array}$} \\
\hline
\end{tabular}

have evaluated clinical, biochemical, or radiological predictors for failure of percutaneous catheter drainage in acute cholecystitis. Antegrade cholangiography may help to select patients who might benefit from elective surgery. Our study was not designed to evaluate the value of cholangiography after percutaneous catheter drainage. Further prospective studies on this topic are needed.

Although other studies have reported considerable morbidity and mortality from emergency laparoscopic cholecystectomy in high risk patients (up to $41 \%$ and 5\%, respectively), ${ }^{3456}$ we found that 
immediate cholecystectomy in these patients is safe. Major complications occurred in $8 \%$ of patients, which seems acceptable in this category of severely ill patients. Yet it should be emphasised that the results of this trial only apply to patients with an APACHE II score of 7 or more and 14 or less, and so do not apply to patients with a score of 15 or more. During the study period, however, we only excluded 10 patients on the basis of this criterion. This implies that virtually all patients with acute calculous cholecystitis can safely undergo early laparoscopic cholecystectomy. As opposed to percutaneous catheter drainage, cholecystectomy is a definitive treatment for gallstone related disease, which does not require readmissions and other interventions that impact patient's quality of life and are a burden on hospital capacity for emergency and elective care. It may be clear that, in patients with a strict contraindication for surgery, percutaneous drainage is still an appropriate treatment, either as a bridge to surgery or as definite treatment.

\section{Conclusion}

Among high risk patients with acute cholecystitis, laparoscopic cholecystectomy compared with percutaneous drainage is the preferred treatment strategy from both a clinical and economical point of view.

\section{AUTHOR AFFILIATIONS}

${ }^{1}$ Department of Surgery, St Antonius Hospital, 3435CM, PO box 2500, Nieuwegein, Netherlands

${ }^{2}$ Department of Surgery, University Medical Centre Utrecht, Utrecht, Netherlands

${ }^{3}$ Department of Surgery, Gelre Hospital, Apeldoorn, Netherlands

${ }^{4}$ Department of Surgery, Academic Medical Centre, Amsterdam, Netherlands

${ }^{5}$ Department of Surgery, Catharina Hospital, Eindhoven, Netherlands

${ }^{6}$ Department of Clinical Epidemiology, St Antonius Hospital, Nieuwegein, Netherlands

${ }^{7}$ Department of Surgery, Onze Lieve Vrouwe Gasthuis, Amsterdam, Netherlands

${ }^{8}$ Department of Surgery, Tergooi Hospital, Hilversum, Netherlands

${ }^{9}$ Department of Surgery, Gelderse Vallei Hospital, Amsterdam, Netherlands

${ }^{10}$ Department of Surgery, Reinier de Graaff Hospital, Delft,

Netherlands

${ }^{11}$ Department of Surgery, Diakonessenhuis, Utrecht, Netherlands

${ }^{12}$ Department of Surgery, VU University Medical Centre, Amsterdam, Netherlands

${ }^{13}$ Department of Surgery, Amphia Hospital, Breda, Netherlands

${ }^{14}$ Department of Radiology, St Antonius Hospital, Nieuwegein, Netherlands

The results of this trial were published in CSL's thesis entitled "Optimal treatment of acute cholecystitis." Utrecht University, Netherlands, 2017.

Contributors: PvD, MGHB, DJG, GAPN, JCK, SCD, AAWVG, PMK, DR, KK, AP, DvdP, RMPHC, BVR, TLB, and DB participated in the design of the study. CSL, PvD, MGHB, DJG, GAPN, JCK, SCD, AvG, PMK, DR, KK, VK, AP, DvdP, RMPHC, BVR, TLB, and DB collected data. CSL, HCVS, and JK did the statistical analysis. CSL, HVC, JCK, and DB interpreted the data. CSL drafted the first version of the manuscript. CSL, HCvS, and DB drafted the subsequent versions of the manuscript. DB is guarantor. All authors read and appraised the report and approved the final version of the manuscript.

Funding: This trial was supported by the St Antonius Research Foundation. The funding source had no role in study design, data collection, data analysis, data interpretation, or writing of the report.
The first author received funds from the Dutch Endoscopic Surgery Society to support publication of her thesis, which included the results of this trial.

Competing interests: All authors have completed the ICMJE uniform disclosure form at www.icmje.org/coi_disclosure.pdf declare no support from any organisation for the submitted work, no financial relationships with any organizations that might have an interest in the submitted work, and no other relationships or activities that could appear to have influenced the submitted work.

Ethical approval: This study was approved by the institutional review board of the St Antonius Hospital, Nieuwegein, Netherlands (NL33662.100.10), as well as by the institutional review board of each participating centre. All patients gave informed consent.

Data sharing: A full dataset is available from the corresponding author at d.boerma@antoniusziekenhuis.nl, contingent on approval from the institutional review board at the St Antonius Hospital, Nieuwegein, Netherlands. Consent was not obtained for data sharing but the presented data are anonymized and risk of identification is low.

Transparency: The lead author (DB) affirms that the manuscript is an honest, accurate and transparent account of the study being reported, and follows the CONSORT guidelines for the reporting of clinical trials. No important aspects have been omitted, and any discrepancies from the study as planned have been explained.

This is an Open Access article distributed in accordance with the Creative Commons Attribution Non Commercial (CC BY-NC 4.0) license, which permits others to distribute, remix, adapt, build upon this work non-commercially, and license their derivative works on different terms, provided the original work is properly cited and the use is noncommercial. See: http://creativecommons.org/licenses/by-nc/4.0/.

1 Wadhwa V, Jobanputra Y, Garg SK, Patwardhan S, Mehta D, Sanaka MR. Nationwide trends of hospital admissions for acute cholecystitis in the United States. Gastroenterol Rep (Oxf) 2017;5:36-42. doi:10.1093/gastro/gow015

2 Keus F, Gooszen HG, van Laarhoven C). Open, small-incision, or laparoscopic cholecystectomy for patients with symptomatic cholecystolithiasis. An overview of Cochrane Hepato-Biliary Group reviews. Cochrane Database Syst Rev 2010;(1):CD008318.

3 Ambe PC, Weber SA, Christ H, Wassenberg D. Primary cholecystectomy is feasible in elderly patients with acute cholecystitis. Aging Clin Exp Res 2015;27:921-6. doi:10.1007/s40520-015-0361-0

4 Fukami Y, Kurumiya Y, Mizuno K, Sekoguchi E, Kobayashi S. Cholecystectomy in octogenarians: be careful. Updates Surg 2014;66:265-8. doi:10.1007/s13304-014-0267-y

5 Nikfarjam M, Yeo D, Perini M, et al. Outcomes of cholecystectomy for treatment of acute cholecystitis in octogenarians. ANZ J Surg 2014:84:943-8. doi:10.1111/ans.12313

6 Winbladh A, Gullstrand P, Svanvik J, Sandström P. Systematic review of cholecystostomy as a treatment option in acute cholecystitis. HPB (Oxford) 2009:11:183-93. doi:10.1111/j.1477-2574.2009.00052.x

7 Miura F, Takada T, Strasberg SM, et al, Tokyo Guidelines Revision Comittee. TG13 flowchart for the management of acute cholangitis and cholecystitis. J Hepatobiliary Pancreat Sci 2013;20:47-54. doi:10.1007/s00534-012-0563-1

8 Jang WS, Lim JU, Joo KR, Cha IM, Shin HP, Joo SH. Outcome of conservative percutaneous cholecystostomy in high-risk patients with acute cholecystitis and risk factors leading to surgery. Surg Endosc 2015;29:2359-64. doi:10.1007/s00464-014-3961-4

9 Sanjay P, Mittapalli D, Marioud A, White RD, Ram R, Alijani A. Clinical outcomes of a percutaneous cholecystostomy for acute cholecystitis: a multicentre analysis. HPB (Oxford) 2013;15:511-6. doi:10.1111/j.1477-2574.2012.00610.x

10 Kortram K, van Ramshorst B, Bollen TL, et al. Acute cholecystitis in high risk surgical patients: percutaneous cholecystostomy versus laparoscopic cholecystectomy (CHOCOLATE trial): study protocol for a randomized controlled trial. Trials 2012;13:7. doi:10.1186/1745-6215-13-7

11 Hirota M, Takada T, Kawarada Y, et al. Diagnostic criteria and severity assessment of acute cholecystitis: Tokyo Guidelines. J Hepatobiliary Pancreat Surg 2007;14:78-82. doi:10.1007/s00534-006-1159-4

12 Knaus WA, Draper EA, Wagner DP, Zimmerman JE. APACHE II: a severity of disease classification system. Crit Care Med 1985;13:818-29. doi:10.1097/00003246-198510000-00009

13 Dutch Guidelines for the treatment of gallstone disease. Available at: https://richtlijnendatabase.nl/richtlijn/galsteenlijden/ galsteenlijden - startpagina.html 
14 Yamashita Y, Takada T, Strasberg SM, et al, Tokyo Guideline Revision Committee. TG13 surgical management of acute cholecystitis. / Hepatobiliary Pancreat Sci 2013;20:89-96. doi:10.1007/s00534-012-0567-x

15 Kortram K, de Vries Reilingh TS, Wiezer MJ, van Ramshorst B, Boerma D. Percutaneous drainage for acute calculous cholecystitis. Surg Endosc 2011;25:3642-6. doi:10.1007/s00464-011-1771-5

16 Chang YR, Ahn YJ, Jang JY, et al. Percutaneous cholecystostomy for acute cholecystitis in patients with high comorbidity and re-evaluation of treatment efficacy. Surgery 2014;155:615-22. doi:10.1016/j.surg.2013.12.026

17 McKay A, Abulfaraj M, Lipschitz J. Short- and long-term outcomes following percutaneous cholecystostomy for acute cholecystitis in high-risk patients. Surg Endosc 2012;26:1343-51. doi:10.1007/s00464-011-2035-0

18 Horn T, Christensen SD, Kirkegård J, Larsen LP, Knudsen AR, Mortensen FV. Percutaneous cholecystostomy is an effective treatment option for acute calculous cholecystitis: a 10-year experience. $H P B$ (Oxford) 2015;17:326-31. doi:10.1111/hpb.12360

19 Ha JP, Tsui KK, Tang CN, Siu WT, Fung KH, Li MK. Cholecystectomy or not after percutaneous cholecystostomy for acute calculous cholecystitis in high-risk patients. Hepatogastroenterology 2008:55:1497-502.

20 Griniatsos J, Petrou A, Pappas P, et al. Percutaneous cholecystostomy without interval cholecystectomy as definitive treatment of acute cholecystitis in elderly and critically ill patients. South Med 12008:101:586-90. doi:10.1097/SMI.0b013e3181757b77

21 Melloul E, Denys A, Demartines N, Calmes JM, Schäfer M. Percutaneous drainage versus emergency cholecystectomy for the treatment of acute cholecystitis in critically ill patients: does it matter? World J Surg 2011;35:826-33. doi:10.1007/s00268-011-0985-y

22 Jang WS, Lim JU, Joo KR, Cha JM, Shin HP, Joo SH. Outcome of conservative percutaneous cholecystostomy in high-risk patients with acute cholecystitis and risk factors leading to surgery. Surg Endosc 2015;29:2359-64. doi:10.1007/s00464-014-3961-4
23 Boules M, Haskins IN, Farias-Kovac M, et al. What is the fate of the cholecystostomy tube following percutaneous cholecystostomy? Surg Endosc 2017;31:1707-12. doi:10.1007/s00464-016-5161-x

24 Granlund A, Karlson BM, Elvin A, Rasmussen I. Ultrasound-guided percutaneous cholecystostomy in high-risk surgical patients. Langenbecks Arch Surg 2001;386:212-7. doi:10.1007/ s004230100211

25 Chok KS, Chu FS, Cheung TT, et al. Results of percutaneous transhepatic cholecystostomy for high surgical risk patients with acute cholecystitis. ANZ J Surg 2010;80:280-3. doi:10.1111/j.1445-2197.2009.05105.x

26 Leveau P, Andersson E, Carlgren I, Willner J, Andersson R. Percutaneous cholecystostomy: a bridge to surgery or definite management of acute cholecystitis in highrisk patients? Scand J Gastroenterol 2008;43:593-6. doi:10.1080/00365520701851673

27 Welschbillig-Meunier K, Pessaux P, Lebigot J, et al. Percutaneous cholecystostomy for high-risk patients with acute cholecystitis. Surg Endosc 2005;19:1256-9. doi:10.1007/s00464-004-2248-6

28 Koebrugge B, van Leuken M, Ernst MF van Munster I, Bosscha K. Percutaneous cholecystostomy in critically ill patients with a cholecystitis: a safe option. Dig Surg 2010;27:417-21. doi:10.1159/000308460

29 Morse BC, Smith JB, Lawdahl RB, Roettger RH. Management of acute cholecystitis in critically ill patients: contemporary role for cholecystostomy and subsequent cholecystectomy. Am Surg 2010;76:708-12

Supplementary information: appendix 